University of Michigan Law School

University of Michigan Law School Scholarship Repository

Law \& Economics Working Papers

$1-1-2014$

\title{
What Boilerplate Said: A Response to Omri Ben-Shahar (and a Diagnosis)
}

\author{
Margaret Jane Radin \\ University of Michigan Law School, mjradin@umich.edu
}

Follow this and additional works at: https://repository.law.umich.edu/law_econ_current

Part of the Contracts Commons, and the Torts Commons

\section{Working Paper Citation}

Radin, Margaret Jane, "What Boilerplate Said: A Response to Omri Ben-Shahar (and a Diagnosis)" (2014). Law \& Economics Working Papers. 98.

https://repository.law.umich.edu/law_econ_current/98

This Article is brought to you for free and open access by University of Michigan Law School Scholarship Repository. It has been accepted for inclusion in Law \& Economics Working Papers by an authorized administrator of University of Michigan Law School Scholarship Repository. For more information, please contact mlaw.repository@umich.edu. 
Radin:

\title{
What Boilerplate Said: A response to Omri Ben-Shahar (and a Diagnosis)
}

\author{
by Margaret Jane Radin*
}

\section{Introduction}

The problem posed by boilerplate (the fine-print purported "contracts" deployed by firms on a take-it-or-leave-it basis) has recently achieved notice in the public sphere. The Consumer Financial Protection Board has investigated and held public hearings on a regulation to limit mandatory pre-dispute arbitration clauses in consumer financial contracts, a process that is mandated by the Dodd-Frank Act of 2010. ${ }^{1}$ Consumer organizations and legal practitioners have focused renewed energy on the problem. ${ }^{2}$ Legal scholars of various schools of thought have also given renewed attention to boilerplate." Old-school "Chicago" law-and-economics seems to be giving way to a more nuanced theoretical approach, ${ }^{4}$ a more nuanced empirical approach, ${ }^{5}$ and, in some quarters, a turn toward behavioral economics. ${ }^{6}$ Scholars whose approach is based

\footnotetext{
*Henry King Ransom Professor of Law, University of Michigan. This essay responds to a book review by Omri Ben-Shahar, available at ssrn.com/abstract $=2255161$. For patient consultations, the author is grateful to Theresa Amato, Patricia Cain, Bruce Frier, and especially Robin B. Kar.

${ }^{1}$ See http://files.consumerfinance.gov/f/201312 cfpb arbitration-study-preliminaryresults.pdf

${ }^{2}$ For example, Citizen Works (faircontracts.org); National Association of Consumer Advocates, Public Citizen, National Consumer Law Center; and many others.

${ }^{3}$ For example, NANCY S. KIM, WRAP CONTRACTS: FOUNDATIONS AND RAMIFICATIONS (Oxford 2013).

${ }^{4}$ See, e.g., Albert H. Choi \& Kathryn E. Spier, Should Consumers be Permitted to Waive Products Liability? Product Safety, Private Contracts, and Adverse Selection, --- J. OF L., ECON, \& ORGANIZATION -- (forthcoming 2014)(arguing that "the social planner should consider either requiring all firms to offer full damages, for instance, by prohibiting consumers from waiving products liability, or mandating a liability level that is less-than-full but provides better deterrence incentives to firms").

${ }^{5}$ See, e.g., Yannis Bakos, Florencia Marotta-Wurgler and David R. Trossen, Does Anyone Read the Fine Print? Testing a Law and Economics Approach to Standard Form Contracts, NYU Center for Law, Economics \& Organization, Law and Economics Research Paper Series 2009, J. LEGAL STUDIES (forthcoming)(results "cast doubt on the relevance of the informed minority mechanism in a specific market where it has been invoked by both theorists and courts").

6 See, e.g., Russell B. Korobkin, Bounded Rationality, Standard Form Contracts, and Unconscionability, 70 U. CHICAGO L. REV. 1203 (2003); Oren Bar-Gill, SEDUCTION BY CONTRACT (Oxford 2013).
} 
primarily on non-economic commitments of polity, of morality, of the rule of law, of the requirements of civil society, are also entering the fray. I am one of the latter, and my book is called Boilerplate: The Fine Print, Vanishing Rights, and the Rule of Law.

Omri Ben-Shahar, at least according to my reading of his oeuvre, is fairly characterizable as primarily committed to old-school Chicago, whereas I am committed to a form of pragmatic legal and philosophical analysis that is difficult or impossible to analyze perspicuously in Chicago mode. These incompatible perspectives makes BenShahar an odd choice to review this book, but his review prompts consideration of the role of tacit preconceptions ("priors"). In its failure to join issue with the main theses of the book, his review is an object lesson for any of us (and I think that means all of us) who are committed to a particular point of view or way of looking at the world. We are always in danger of reading a text in a way that confirms our priors, our background commitments and assumptions about what people who disagree with us must be thinking. We are also always in danger of failing to see aspects of debates or data that do not fit well into our preconceptions; and then we are likely to think that this kind of failure amounts to an argument against certain positions in the debate or an argument against the relevance of that kind of data.

\section{Autonomy (and Contract Theory)}

Ben-Shahar begins by reading Boilerplate as if it elevates some theory of autonomy to a pedestal where it invalidates all boilerplate, but the book doesn't do that. He then argues against the proposition that the book did not advance. He trots out the old-school Chicago analysis of consumer choice, his version of autonomy: consumers are choosing, or would choose if rational, or should be understood to have hypothetically chosen, to yield up legal rights contained in boilerplate because the products or services will be cheaper, and consumers are thereby preferring cheapness to rights--which Chicagoans construe as nothing other than better quality of product. Yet in Boilerplate, unlike in Ben-Shahar's apparent priors, rights occupy a different category from product qualities, both from the point of view of what kind of values they represent, and from the point of view of their relationship to society as a whole rather than only to individuals.

But to start with Ben-Shahar's starting point: Ben-Shahar thinks Boilerplate says that "the fine print is not a contract" ( $\mathrm{p}$ [1]) Boilerplate does not say that. Nor does it say anything so categorical or general. Boilerplate says instead that sometimes-perhaps often--mass-market boilerplate deployed against consumers (or entities in the position of consumers) would be better regulated in other ways than contract law. The book examines in detail the why and the how of this position. Ben-Shahar ignores the detail because his background assumptions caused him to set up a straw man. He thought he knew what someone would say who doesn't think boilerplate is mostly or presumptively valid and enforceable, and proceeded to characterize what Boilerplate said as if it said that. ${ }^{7}$

${ }^{7}$ Right off the bat, Ben-Shahar misrepresents me by using a truncated quotation, according to which I say, referring to boilerplates: "They should be declared invalid in toto, and recipients 
Boilerplate is not a book that elevates autonomy to any pedestal. It is instead an effort to gather together into one book many strands of thought about boilerplate - in economics, in the main varieties of contract theory, in the practice of US courts, in regulatory efforts in the US and elsewhere-so that we can better see opportunities for improvement in how we deal with boilerplate. One problem Boilerplate brings to our attention is that the prevalent justifications for contract enforcement - which after all is a form of state coercion - rely on conceptions of voluntariness that just don't exist very often, especially with some varieties of boilerplate. This is not the end of an analysis, but rather a place to begin. Boilerplate gathers together into one book a broad range of ideas relevant to boilerplate, in order to encourage readers to consider opportunities for improving our theory and practice. In the second half of the book, I suggest some of those opportunities myself. Among other things, I make detailed suggestions on how judges could improve on unconscionability and public policy decisions, how market initiatives might be harnessed to cabin boilerplate excesses, and how really bad boilerplate might be regulated by tort law rather than contract law. Ben-Shahar's review unfortunately does not convey the nature of this book to possible readers. ${ }^{8}$

should be governed by the background default rules.” (pp [1]-[2] ) But what I actually said, in a late chapter discussing possible tort remedies (referring to a time before we have thought through the details of how a tort remedy should work) was: "Meanwhile, my preliminary suggestion is that a purported contract containing offending boilerplate should be declared invalid in toto, and recipients should instead be governed by the background legal default rules." In this preliminary suggestion I referred to "offending" boilerplate - meaning mass-market boilerplate that is bad enough to incur tort liability for intentional deprivation of core legal rights.

There are other instances of misrepresentation, but I won't go on about them. I am not sure how to diagnose this misrepresentation. I don't see how a thorough reading of the book by a scholar as intelligent and knowledgeable as Ben-Shahar could have left him with the impression of my views that he seems to have. Perhaps his priors are that strong, and what he considered confirming evidence just caught his attention. Although the view Ben-Shahar attributes to me in his review is not mine, it allows him to use it as a foil for his own forthcoming book (with Carl Schneider), More Than You Wanted to Know: The Failure of Disclosure (forthcoming Princeton 2014). In his book, Ben-Shahar observes problems with recipients' understanding of boilerplate; the main thrust of his book is a sustained argument against those who support heightened disclosure requirements as a solution. It is strange that in his review of my book he spends so much time on this debate, since -as Ben-Shahar notes at one point-I explicitly disavow heightened disclosure regulations as an appropriate solution to bad boilerplate. I agree with him about disclosure and I say so. Perhaps Ben-Shahar has been thinking so intensely about a certain class of problems that he has become fixated on a particular framing, a framing that is also supported by his particular preconceptions, and this has made it hard to see the distinctive contribution of Boilerplate. Unfortunately, the result is a review that offers a much better introduction to the themes of his own book than to mine.

${ }^{8}$ Instead, Ben-Shahar devotes much space to his characterization of me as an "autonomist." $\mathrm{He}$ also gathers under the "autonomist" label various theorists who believe that the problems of consent can be solved with better disclosure, see note 7, supra, which he himself doesn't believe-and neither do I. It tends to obfuscate matters that Ben-Shahar says autonomists believe a certain thing (that disclosure will be generally useful) which I don't believe, yet he refers to me as an 


\section{Normative Degradation}

It's true that I believe that a lot of mass-market boilerplate should not be treated as contract. That is a jumping-off point to the gravamen of the book. To put it most simply, (1) enforcement of contract is a form of government coercion; (2) what is supposed to justify that coercion is the liberal story that undergirds private ordering; (3) that liberal story assumes that parties to contracts have voluntarily agreed to an exchange for mutual benefit; (4) that rationale is spread thin beyond the breaking point when it comes to much of the mass-market boilerplate world; (5) and, so far, we don't have a better rationale.

This situation - that is, the disjuncture between the traditional rationale for contract enforcement and the phenomenon of boilerplate, which I called "normative degradation"-- really occupied only the first couple of chapters of Boilerplate, and should be seen as an entry point for further analysis. For example in Chapter 10, which I thought might receive some nods of approval from Chicagoans, I considered situations where market responses can operate to curtail bad boilerplate schemes. ${ }^{9}$ Such market responses can sometimes be effective. But they will be less effective where the rights deleted by the boilerplate are not salient for recipients, as legal remedies typically are not. We never think we are going to need to sue someone; injury from a negligent service provider always happens to the other fellow. This type of heuristic bias is now recognized in behavioral economics, but hasn't fully permeated old-style Chicago yet.

What I want to convey with the term "normative degradation" is an understanding of the disjuncture between, on the one hand, the traditional status of the normative force of the justification on which we rely when we sanction state enforcement of contracts, and, on the other hand, the sort of slippery slope to which that normative commitment has traversed in order to provide endorsement for many of today's allegedly contractual phenomena that affect massive swaths of the populace. Where else but in the field of contract law would we have judges examining whether somebody who did not see

"autonomist." Of course, he is an "autonomist" too, if he believes, as most law-and-economics theorists do, that "freedom of contract" is an important ideal of our society and that it depends on something known as "freedom of choice"--which is, of course, a version of autonomy. We don't have any story to replace the liberal story of why contract enforcement by the state is justified, and the liberal story does depend upon voluntariness. So a perspicuous argument here cannot be about whether one is an autonomist or not; rather, the argument has to be about exactly what sort of autonomist one is, and exactly what role the question of autonomy should play with respect to problems posed by various uses of boilerplate. Unfortunately, Ben-Shahar's broad-brush treatment of "autonomists" doesn't raise the question of what version of autonomy is appropriate; and, indeed, economic theorists rarely tackle it, except in a sub rosa way. See ch. 6 of Boilerplate; see also my response to Abraham Wickelgren: Radin, Form Contracts and the Problem of Consumer Information, 167 J. INSTITUTIONAL \& THEORETICAL ECONOMICS 49 (2011)

${ }^{9}$ For example, seals of approval, rating agencies, technological filtering approaches or even machine bargaining. All of these have their pros and cons, of course, which I need not recapitulate here. 
something and would not have understood it if he did see it should nevertheless be declared to have agreed to it? Where else does a third party's view that I would have had an opportunity to see something I didn't see make me liable for it? If contract theory is not a good fit for the phenomenon of boilerplate, we should look for some new and better theories, and that is an important part of what Boilerplate is about, in the end.

\section{An Improved Analysis for Judges}

Yet if courts insist on treating mass-market boilerplate deployed by firms against recipients as contract, I argue that at least they could implement an improved analysis. Therefore I argue for a complex tripartite evaluation template to help common-law judges decide when mass-market boilerplate should be disallowed. This is a proposed improvement on the common-law adjudication tools of unconscionability and void as against public policy. It asks judges to take into account (1) the nature of the right; (2) the quality of consent; and (3) the extent of social dissemination of the boilerplate scheme (how many recipients are subject to it). It is still my hope that judges (and their law clerks) will look into my suggestions here and see whether the analysis makes sense. ${ }^{10}$

Why is it important to take into account not only consent, but two other factors? The nature of the right matters because some rights cannot be traded off in markets no matter how good the consent, and some rights should be at least deserving of stricter scrutiny before a judge decides they can be traded off by boilerplate. Considering the nature of the right being deleted invites consideration of market-inalienability, or partial market-inalienability. ${ }^{11}$ This means that even if recipients are actually consenting, such consent should not operate to divest them of certain kinds of rights. The quality of consent remains relevant as well, because all three parameters require judgment: if consent looks dubious, the decision maker should take its dubiousness more into account if the nature of the right also looks as if it may be something that is important to civil society as a whole. The extent of social dissemination also matters in this tripartite analysis, because the kinds of rights that are most important to view through this lens are those that recipients of boilerplate do not consider important to them personally, but which are really important to civil society and the rule of law, so that the more people are burdened with deletion of such rights, the more it becomes an issue for the rule of law and for equality before the law. The analysis I propose is designed to help us focus on rights of redress of grievances, and especially access to feasible redress of grievances in

\footnotetext{
${ }^{10}$ Among other things, it will be important to recognize and avoid the truly mischievous ambiguity caused by the prevalent "reasonable expectation" trope. The more the world around us is unjust, the more we would empirically expect to be unjustly treated; yet the normative expectation is still that this is injustice. See also, Margaret Jane Radin, An Analytical Framework for Legal Evaluation of Boilerplate, in PHILOSOPHICAL FOUNDATIONS OF CONTRACT LAW (George Letsis, Gregory Klass, and Prince Saprai, eds., forthcoming 2014, Oxford University Press).

${ }^{11}$ I have explored these concepts in detail in an earlier book, CONTESTED COMMODITIES (Harvard 1996).
} 
practice. $^{12}$ Because of the contemporary burgeoning of widespread boilerplate rights deletions in the US, it is time for us to consider whether rights to feasible redress should be alienable by individuals as easily as rubber-stamp boilerplate enforcement accomplishes. ${ }^{13}$

\section{The Problem of "Fit"}

Because justification of state enforcement of contracts is dependent on versions of the liberal story, what happens if the story is not plausible for a substantial percentage of alleged contracts? That is the question raised by certain varieties of mass-market boilerplate. It is an instance of the general problem of "fit" between an ideal justification and non-ideal circumstances in real life. This is indeed an old problem in political theory. How far can a practice diverge from its ideal justificatory story (fail to be described by this story) and still be considered justified as an instance of it? How good a "fit" between theory and practice do we need?

In Boilerplate I did not attack the "fit" problem in general. It is a difficult and rather abstract issue in political theory. It is critical to keep in mind, however, that I did not argue (as Ben-Shahar might have assumed) that all contracts that don't fit the story perfectly are thereby to be deemed unjustified and unenforceable. Perhaps no contracts in the real world ever have the level of information and understanding on each side that would fulfill the ideal, that would fit the liberal story perfectly. Yet we do think that many real-world contracts are close enough. ${ }^{14}$

\footnotetext{
${ }^{12}$ Legal remedies are not usually salient for individuals. Most of us never think we are going to be the unlucky one that needs to use a legal remedy. The fact that people will willingly give up legal remedies for a few nickels just means they think disaster only happens to the other fellow. But among us there are unlucky people whose child or elderly relative is maimed at a care center through obvious negligence, yet the care center is exonerated by an exculpatory clause. And there are unlucky people who want to sue an employer for discrimination but find that federal antidiscrimination rights cannot be brought into court before a jury, but have been shunted to arbitration. These unlucky people are likely to find that federal anti-discrimination rights cannot be brought as a class action which is often the only way to prove discrimination. Ben-Shahar would better join issue in arguing about the various theses in Boilerplate had he chosen to tackle these examples instead of the ones he does give us (mobile phone buyers, airline ticket buyers, etc). Of course, I do understand that for an old-school Chicagoan, legal rights are as fungible as airline seat room. Nevertheless, my view is that issues regarding whether a right can be treated as fungible must be addressed; and we cannot do that using the Chicago theoretical paradigm that assumes fungibility.

${ }^{13}$ The widespread deletion of feasible avenues of redress is not the only right important to civil society as a whole with which Boilerplate is concerned. Nevertheless, I will leave to readers of the book the question of which other rights might fit into a category of permanently or presumptively situated in the public realm.

${ }^{14}$ There is an interesting question what we should think of boilerplate between sophisticated parties. We have yet to see much theorizing about this, though we know it occurs in practice. See Mitu Gulati and Robert Scott, THE 3-1/2 MINUTE TRANSACTION (2013)(outlining various
} 
Ben-Shahar may have meant to apply a reductio argument: that Boilerplate implies that even the simplest contracts would have issues about consent. This would miss the point: there is a great difference between contemporary widespread market rights deletions and how they are allegedly assimilated to classical contract theory versus the kinds of minor deviations from justificatory theory that we can readily accept. I think there must be a metaphorical continuum of how close the "fit" between justification and practice must be. At some point, certain alleged contracts are just too far from the alleged justification to be allowed as contracts; they fall off the end of the continuum. That is what I think is true of certain kinds of mass-market boilerplate rights deletions, especially (but not exclusively) those that try to do away with any usable avenue of legal redress. In other words, I think we can tell what is off the end of the continuum without being able to lay out exactly how a theory of "fit" must work.

The kinds of mass-market boilerplate rights deletions that are particularly problematic are those that delete legal remedies, including those that make redress unavailable in practice. That would include remote choice of law/choice of forum clauses, outright exculpatory clauses, mandatory pre-dispute arbitration clauses, ${ }^{15}$ class relief waivers. ${ }^{16}$ ) The rule of law cannot exist without legal remedies, and that means effective remedies, not remedies in name only. ${ }^{17}$ Mass-market boilerplate can divide

possible explanations for persistence of mischievous old boilerplate between sophisticated players in the sovereign bond market and concluding its survival was probably due to agency costs associated with "big law").

${ }^{15}$ As Boilerplate lays out in chapter 7, mandatory pre-dispute arbitration clauses would accord relief (if any) that is secret and non-precedential. They would destroy the idea of common-law precedent if prevalent enough. It is often thought, too, that arbitrators come from the ranks of firms' colleagues, and are unfriendly to consumers. They are repeat players that are chosen by industry, and they may harbor unconscious bias in the industry's favor if they want to continue being chosen as an arbitrator. The track record on arbitration shows that it is successful for consumers in a miniscule percentage of cases.

${ }^{16}$ Without some kind of aggregate relief, firms can get away with repetitive small gouging on a continuous basis, because obtaining relief would cost more than it is worth to an individual. That is the well-known rationale why legislative bodies enact aggregate relief. Scalia, J., with his cohort of 4 conservative activist colleagues, holds that the Federal Arbitration Act trumps all other federal protections for individuals when a "contract" --boilerplate deployed by a powerful firm - effectively precludes any relief by shunting recipients to arbitration and precluding class actions. American Express v. Italian Colors Restaurant, _US_(June 20, 2013). (The elevation of "contract" over federal rights other than the one the FAA offers has to my mind an echo of Lochner about it.)

${ }^{17}$ See Chapter 3 on democratic degradation; see also Margaret Jane Radin, Boilerplate: A Threat to the Rule of Law? in Lisa Austin \& Dennis Klimchuk, eds., PRIVATE LAW AND THE RULE OF LAW (forthcoming, Oxford 2014). Democratic degradation refers to undermining the Rule of Law. But in its simplest form, it refers to the way mass-market boilerplate can simply "repeal" what democratic bodies have enacted. (Unless those bodies make the rights they consider important non-waivable, which has happened; e.g. in landlord-tenant law sometimes; see also Choi \& Spier, supra note 4) Although I didn't write about this in Boilerplate, democratic degradation can also refer to capture of legislatures and agencies by powerful rent-seekers. 
society into a group that has access to legal remedies and a group that doesn't, so it's a threat as well to equality before the law.

\section{The Chicago Answer}

It's important to scrutinize the standard argument endorsed by businesses and their lawyers, seemingly stemming from old-school Chicago law and economics, an argument to which Ben-Shahar seems to subscribe. It is the following kind of blanket argument: the business will save money by deleting its consumers' legal rights; the business will pass on these savings to the consumer; the consumer who buys the product or service necessarily values her legal rights less than the amount of the price reduction; therefore the consumer is choosing (or should be assumed to be "rational" and therefore hypothetically to choose) to sell off her individual rights for the price reduction. This argument has the advantage of at least seeming to move away from the standard template in contract theory, in which we suppose that two equally independent and cognizant and free individuals are entering into a trade with each other.

What is wrong with this standard argument promoted by many businesses and their supporters? Lots. It cannot be empirically valid in the general, across-the-board sense in which many advocates use it. What licenses the assumption that savings are passed on rather than pocketed by the firm? The argument depends on the existence of a competitive market (or something close to it), and on lack of information asymmetry (or something close to it); that means, the presence of the right amount of savvy shoppers who can set demand, and a situation where the firm must charge the same price to all (or to not too many segmentations). ${ }^{18}$ The argument assumes that the amount of the

\footnotetext{
${ }^{18}$ Indeed this situation is complained of as cross-subsidy, as Ben-Shahar does, by those who believe this scenario describes most markets in which boilerplate appears, as Ben-Shahar does. Of course, the kinds of rights that are in the care of the polity are supposed to involve "crosssubsidy" because (except in Chicago-land?) we are supposed to have equality before the law. (Note that there is now empirical work casting doubt on the generalized informed minority thesis; see note 5 , supra.)
}

In a short footnote ( $\mathrm{p}$ [12]), which is his only notice of my extensive treatment of this popular argument by Chicago law-and-economics writers, Ben-Shahar notes that "Chapter 6 of the book discusses the view that boilerplate is merely a feature of the product," which indeed is what many Chicago law-and-economics folks are now arguing. See e.g., Douglas Baird, The Boilerplate Puzzle, 104 MICH. L. REV. 933 (2006), as reprinted in BOILERPLATE: THE FOUNDATION OF MARKET CONTRACT 131 (Omri Ben-Shahar, ed., 2007).

In that footnote Ben-Shahar goes on to mention that my chapter argues that even if we assume markets are competitive, efficiency would not result, "due to imperfect information." Yes, indeed. Consumers have less information that those who deploy boilerplate, and even in a competitive market this may result in a race to the bottom (a so-called "lemons equilibrium"); and, of course, not all markets with mass-market boilerplate are competitive. These are part of the reasons that I argue that the blanket empirical assumptions that boilerplate enforcement is efficient are questionable. It's also questionable to believe that just because a lot of firms have the same 
supposed price reduction is exactly the amount at which the consumer values (or would hypothetically value) his legal right. These are primarily empirical assumptions that would require empirical research, market by market. ${ }^{19}$

But even in cases where the empirical assumptions might hold, Boilerplate makes a different point. The Chicago argument that Ben-Shahar seems to espouse is much more normatively problematic than the standard normative grounds for contract enforcement. It rests on different premises, such as the premise that all rights accruing to individuals are fungible and tradable (except maybe for bodily integrity, or whatever exceptions the theorist may wish to assume). We cannot perspicuously address these problematic premises with the standard voluntariness assumptions of traditional contract theory and rationality assumptions of older versions of economic analysis. At least we should grant that the case is not simple, the problems are thorny. For example, we can't just assume that firms can "condemn" recipients' legal rights. That is a massive conversion of property rules into liability rules. ${ }^{20}$ And even if individuals were giving actual real consent, there are some rights that cannot be sold off by individuals; at least, not without stricter scrutiny (more thought). The issue of market-inalienability, or partial marketinalienability, is not visible to those who think primarily in market rhetoric. The kinds of rights that Ben-Shahar doesn't talk about are the very kinds of rights with which Boilerplate is most concerned.

When Ben-Shahar talks about relinquishment of all of a boilerplate recipient's viable rights to legal remedy as if that were no different from buying an economy ticket rather than a first-class ticket, he is engaging in a characteristic collapse of the distinction between the private realm and the public realm. ${ }^{21}$ As Boilerplate argues, public choice theory (aka political economy theory) undermines the distinction between public and private ordering from the Right, an undermining that has been far more successful than the deconstruction from the Left. Such theorists, of whom Ben-Shahar seems to be one, see no difference between background rights that are in the care of the polity, and rights that the polity allocates to individuals. ${ }^{22}$ Such theorists, as Ben-Shahar does, typically

boilerplate, it must be efficient. There are times when "everybody does it" is not a complete justification, even from an efficiency standpoint.

${ }^{19}$ Though I would say that is not true for the slide from actual consent to assumed rationality to hypothetical consent.

${ }^{20}$ Discussed at length in chapter 4. Even if firms could "condemn" recipients' property rules and effect a massive change from property rules to liability rules, nothing licenses the assumption that the firms are paying the "right" amount for the rights that they are "condemning."

${ }^{21}$ Ben-Shahar's collapse (pages [5]-[7]) of the public and private is clearly played out when he compares a contract that relies on public background rules with a contract that consists of boilerplate imposed by a private firm. Actually my book does explain the distinction that BenShahar collapses here (at pp 93-95).

${ }^{22}$ This includes corporate entities and their contractual activities, of course. In a short footnote which is Ben-Shahar's only reference to my chapter critiquing the "contract-as-product" approach which is now popular among Chicago law-and-economics scholars (see note 18, supra), BenShahar says that the chapter does not address the "more pressing question" of the price effect"whether purchasers of products are well-served by mandatory high-quality terms." But 
begin with economic analysis in market situations (for example, purchase of cell phones). This is a form of reasoning that works well, if at all, for some central cases of voluntary exchange, but its theoretical framework makes it hard to understand other normative situations that have to do with the polity or civil society, and not just individuals. Boilerplate is talking about massive deletions of civil society's background infrastructure of rights. Ben-Shahar's priors tend to make him to think that those rights are not at all different in the type of analysis they demand of us than is the pricing and quality of cell phones that individuals are willing to purchase. All values reduce to price, and all ordering reduces to private ordering.

If all ordering reduces to private ordering, however, the well-known conundrum arises. If everything we do is for the purpose of individual benefit, how can we all cooperate to exit the state of nature and set up a state for the benefit of all? The liberal story has it that the state has certain duties toward us that are what made us willing to exit the state of nature. It can be argued - and I do so argue - that being free of watching one's back constantly, in every daily activity, in caring for children, in seeking recreation, in engaging in work, is one of them. That is why boilerplate exculpatory clauses are a

Boilerplate does address this "pressing question," sometimes on terms that doubt the empirical assumptions upon which the "well-served" idea rests. How can we assume that consumers are well-served by races to the bottom in markets plagued by information asymmetry, even if they are competitive? And how can we assume that consumers are well-served by the dynamics of many non-competitive markets? And why should we assume that all products are cheaper if they come with lousy terms - yes, the firm saves money, but under some market conditions the firm can just pocket the money.

In addition to the unsupported generalities of empirical assumptions, I question the normative upshot of treating consumers as well-served if the only thing to be taken into account is the consumer's own ex ante experienced preference. Consider what terms Ben-Shahar must be talking about when he talks about "mandatory high-quality terms." Here we can see that legal redress of grievances is just a higher quality of commodity, no different than parts that last longer, or are made out of gold instead of silver. For Ben-Shahar, some individuals have ex ante "preferences" for legal rights, but more people have "preferences" for cheapness. But some of the mass-market boilerplate terms to which Boilerplate asks us to devote attention are about limiting or denying access to remedies, about weakening or erasing principles of due process, about undermining equal citizenship. The fact that these are mostly not salient to individuals-do not drive individuals' ex ante experienced preferences--cannot be dispositive of their importance to society. They are not market commodities.

Ben-Shahar has a serious point when he implies in this same footnote that educated and wealthy consumers fare better than poorer consumers under mandated protections. I think this is not true of anti-discrimination remedies, which might be more likely to be sought by poorer people; and it is probably not true of remedies for negligently caused harm to persons by service providers such as day care centers and nursing homes. We do need to confront wealth disparity and the social harms it causes. But why does Ben-Shahar seem to think that we should fix the fallout from wealth disparity by equalizing loss of rights instead of insuring that important background rights are guaranteed for all? 
serious incursion on the commitment to civil society, and should not be theorized as just amounting to purchasing a cheaper product rather than a more expensive one.

\section{Where Do We Go From Here?}

Ben-Shahar seems to think that background rights that are in the care of the polity are a species of "paternalism." That terminology is not what I would like, and I think it leads debate astray. But never mind. Whatever the terminology, we can debate about what rights are in the care of the polity, and that is a debate we should have. I wonder what Ben-Shahar thinks of the idea that firms providing services in many states of the US can exculpate themselves from their own negligence; and I wonder what he thinks of the fact that the exculpatory clause is often written as if any harm caused by the firm, even if intentionally, grossly negligently, or recklessly, is without remedy? ${ }^{23}$ The UCC is more enlightened, perhaps, because even though it allows extremely shrunken remedies for damage caused by defective products; it draws the line at products causing personal injury to a consumer; ${ }^{24}$ and it leaves a savings clause for a judge to decide that shrunken remedies amount to "failure of essential purpose." 25 Should we think that such background rights are themselves waivable by boilerplate? Even if the market context is such that the firm actually is passing on savings rather than pocketing the money, so that the product is cheaper?

I venture to think that even Omri Ben-Shahar might draw the line at some waivers of legal rights. ${ }^{26}$ There are rights that are permanently in the care of the polity, for the benefit of society as a whole. We need to have more discussion of what those rights are, and why. We can't get any traction on this problem by using methods of analysis that reduce all human activity to private market activity and all values to prices. Judges can start by providing stricter scrutiny (more thought and reflection) when a right that comes under a mass-market waiver might be one that should be considered permanently in the care of the polity. Legal scholars can give more serious consideration to this issue in light of the economic realities of our time. Before we conclude that it would destroy our economy to protect background rights by declaring certain rights (particularly remedial rights) non-waivable, or waivable only with extra scrutiny, we should realize that other

\footnotetext{
${ }^{23}$ Economists are apparently starting to disbelieve the standard blanket kind of story to which Ben-Shahar apparently subscribes; see Choi and Spier, supra note 4. It certainly seems, as noted in Boilerplate (pp. 139-40), that exculpatory clauses create a massive moral hazard problem. Insurance companies that will only insure service providers if those providers attempt to shunt the risk to their customers may have a nice racket going. And, at last, empirical work is starting to appear showing that the blanket general kind of story cannot be true in certain specific cases; indeed, in cases that are likely to be important to consumers; see Bakos, et al, supra note 5.

${ }^{24}$ UCC $2-719(3)$

${ }^{25}$ UCC 2- 719(2)

${ }^{26}$ Since Ben-Shahar seems to approve of my suggestion that we consider regulating the worst sort of rights erasures under tort law, I think, for example, that he might be able to agree that deletion of all tort remedies should be disallowed.
} 
countries are not nearly as boilerplate-enforcement-happy as the US, and their economies are not falling apart, at least not any more than the US's is.

\section{Conclusion}

Boilerplate was intended to make a start on the discussion we need to have about the kinds of rights that cannot be easily waived by dropping mass-market boilerplate on thousands or millions of people. It was intended to begin exploration of different methods of dealing with these waivers that fit so uneasily into current contractual models, whether classical or Chicagoan. I thank Ben-Shahar for recognizing (as I hope he did) that these are major goals of Boilerplate, though I am sorry that his review does not inform potential readers of what Boilerplate actually said. 